\title{
Copyright de la memoria, autoficción y novela familiar en Soy un bravo piloto de la nueva China
}

\author{
Jordana Blejmar \\ UNIVERSITY OF LONDON · Jordana.blejmar@sas.ac.uk
}

Investigadora de la Universidad de Londres y miembro del comité directivo del Centre for the Study of Cultural Memory (Londres). Estudió Letras en la Universidad de Buenos Aires y es Doctora en Estudios Culturales Latinoamericanos por la Universidad de Cambridge (Inglaterra) donde también obtuvo una maestría. Forma parte del comité editor del Journal of Romance Studies (en el 2014 publicó allí un dossier sobre postmemorias latinoamericanas co-editado con Natalia Fortuny) y es co-editora (junto a Natalia Fortuny y Luis Ignacio García) de Instantáneas de la memoria. Fotografía y dictadura en Argentina y América Latina (Libraria, 2013).

RECIBIDO: 15 DE DICIEMBRE DE 2013

ACEPTADO: 25 DE ENERO DE 2014

Resumen: Soy un bravo piloto de la nueva China (Semán, 2011) supone una vuelta de tuerca en la representación de la última dictadura militar argentina propuesta por la literatura autoficcional de las generaciones de la postdictadura. Si bien es cierto que existen antecedentes de novelas sobre la dictadura (notables, por cierto) en las que la focalización está puesta del lado de los militares o de sus cómplices, por primera vez es una víctima directa de la dictadura el que le otorga, en la ficción, esa posición de testigo de la historia a un perpetrador. La apuesta fuerte y valiente de Semán descansa en la sospecha de que para entender mejor la historia familiar y nacional, no alcanza con los documentos heredados (cartas y fotos), o con los recuerdos de los que habitan el mundo de los vivos. La autoficción y la literatura le ofrecen lo que no puede el testimonio, la autobiografía o la crónica histórica.

Palabras Clave: Autoficción, memoria, Semán, postmemoria.
Abstract: Soy un bravo piloto de la nueva China (Semán, 2011) marks a shift in the autofictional representation of the last Argentine dictatorship. Like writers from previous generations and also other children of disappeared parents who have written fictional accounts of the period, Semán also grapples with the problem of how to represent perpetrators by including a military officer as a principal character. This novel, however, represents the first time that a direct victim of the dictatorship - Semán's father being disappeared by the military regime - includes, as part of the narrative, the point of view of the perpetrator to bear witness to the traumatic events of recent Argentine history.

Key Words: Autofiction, memory, Semán, postmemory. 
Soy un bravo piloto de la nueva China (Semán, 2011) supone una vuelta de tuerca en la representación de la última dictadura militar argentina propuesta por la literatura autoficcional de las generaciones de la postdictadura. Si otros escritores jóvenes e hijos de desaparecidos ya habían incursionado en el fangoso terreno de la representación del perpetrador, la novela de Ernesto Semán va un paso más allá al ofrecer no solo la imagen ficcional de un represor, sino además su punto de vista sobre los hechos del pasado. Si bien es cierto que existen antecedentes de novelas sobre la dictadura (notables, por cierto) en las que la focalización está puesta del lado de los militares o de sus cómplices, por primera vez es una víctima directa de la dictadura el que le otorga, en la ficción, esa posición de testigo de la historia a un perpetrador.

La apuesta fuerte y valiente de Semán descansa en la sospecha de que para entender mejor la historia familiar y nacional, no alcanza con los documentos heredados (cartas y fotos), o con los recuerdos de los que habitan el mundo de los vivos. La autoficción y la literatura le ofrecen lo que no puede el testimonio, la autobiografía o la crónica histórica: no solo recordar/imaginar la experiencia propia, sino también dos experiencias casi imposibles de, precisamente, imaginar, a saber, la de un padre en el campo de concentración y la de su torturador.

La novela está dividida en tres partes y un epílogo. Cada parte, a su vez, se compone de tres capítulos: "La Ciudad", "El Campo" y "La Isla". Los capítulos titulados "La Ciudad" describen acontecimientos ocurridos en el año 2002 y tienen, según el propio Semán, cierta connotación realista. Refieren al regreso a Buenos Aires de Rubén, un geólogo argentino residente en los Estados Unidos que vuelve a la patria para acompañar a su madre enferma de cáncer en sus últimos días de vida. Los capítulos situados en "El Campo" son de orden histórico y se ocupan del cautiverio del padre de Rubén, el militante maoísta Luis Abdela, secuestrado en un campo clandestino de concentración y luego desaparecido durante la última dictadura militar argentina. Por último, los capítulos de nombre "La Isla" refieren a un espacio y tiempo alegórico o imaginario al que Rubén es mágicamente transportado por un autobús submarino; una isla infernal y onírica regentada por Rudolf, un hombre con cola de mono y su pérfida esposa, The Rubber Lady. En "La Isla”, Rubén se reencuentra con una antigua novia y juntos salen a correr, hacen el amor, y pasan el día tirados en la cama, presenciando fragmentos de su vida y del cautiverio de Luis proyectados en una computadora-escáner como si esas vidas fueran recuerdos de otros, películas o escenas desarrolladas detrás del vidrio de una cámara Gesell.

El trauma de la desaparición de Luis durante la infancia de Rubén funciona como conector entre las tres partes, en tanto que estas ofrecerían explicaciones posibles y distintos puntos de vista a esa situación límite. Las páginas inaugurales introducen, en efecto, el hecho traumático de la muerte del padre para dejar en claro que todo lo que se contará después es causa o consecuencia de ese episodio radical en la vida del protagonista. 
En la primera escena Rubén abre la puerta de su departamento y encuentra a su padre colgado en el medio de la sala. Durante años, confiesa, había fabulado varios posibles suicidios como ese. Lo imaginó saltando por la ventana de una oficina, borracho, drogadicto, sacrificado por una causa mayor, también colgado en el medio de la sala. "El centro de la fantasía era una última y larga, íntima conversación entre nosotros. (...) De tanto haberlo imaginado, todo parecía un poco más normal" (15).

En una lectura apresurada, estas primeras líneas pueden resultar confusas y hasta dan la impresión de no tener ninguna relación con el resto de la historia. A continuación y a lo largo del relato queda claro que Luis no se mató sino que lo mataron, y más aún, que esa muerte no ocurrió durante la adultez de Rubén sino en su infancia. No obstante, el episodio del suicidio de Luis es fundamental para lo que sigue. Primero porque deja sentada la dificultad de explicar/narrar lo inexplicable y advierte así que cualquier intento por transmitir esa experiencia será de algún modo insuficiente. Segundo, porque deja entrever que la novela no será más que esa "larga íntima conversación", ese "encuentro secreto entre generaciones" (para decirlo con Walter Benjamin), que menciona Rubén. De allí que Ricardo Piglia (2011) haya leído Soy un bravo piloto de la nueva China en la tradición de la Carta al Padre. Y tercero, porque establece el pacto autoficcional de lectura desde el que deberá ser abordada toda la historia, donde lo real, lo imaginado, lo fantaseado, lo soñado y lo verosímil se confunden como en una cinta de moebius.

Es en este sentido que no puede leerse la novela de Semán como si fuera un texto autobiográfico, es decir como un texto "regido por una ley suprema: decir (sobre sí mismo y de paso, sobre el otro) la verdad, que está vinculada a la realidad, por oposición, desde luego, a la ficción" (Doubrovsky, 2012: 48). En la novela estas tres categorías -verdad, realidad y ficción- no se oponen sino que se necesitan, pues es la puesta en ficción de su historia familiar lo que le permite al autor acceder a una verdad sobre su pasado (un conocimiento, si se quiere) que poco tiene que ver con la correspondencia entre lo que se cuenta en el libro y lo que realmente ocurrió a la familia Semán en los años negros de la Argentina.

Así y todo, el lector será tentado a leer Soy un bravo piloto... como si fuera un testimonio o una autobiografía. Tramposamente alentado por la novela a establecer correspondencias directas entre autor y personaje, no le costará advertir, por ejemplo, que Rubén y Ernesto son ambos académicos argentinos residentes en Estados Unidos y que los dos tiene el hábito de correr. Además, el padre de Semán está, como Luis Abdela, desparecido.

Para reforzar lo que Philippe Lejeune llamó un pacto autobiográfico con el lector, la novela ofrece además dos "documentos" que vendrían a ratificar esa consubstanciación. Primero, durante una de las escenas en las que El Capitán y Luis conversan, se reproduce un fragmento de un informe en posesión del torturador. Se trata del testimonio del hermano de una persona que habría conocido a Luis, y que cuenta como éste lo interceptó para que 
se encargara de la parte médica de un proyecto militante que Luis y sus compañeros estaban llevando a cabo en una villa. Al final, el informante dice de Luis y de Rosa que "usaban nomes de guerre, ellos, Elías Semán y Susana Bodner, se hacían llamar" (163).

Esta es la primera vez que, mediando la historia, la novela da los nombres reales de los padres del autor. El segundo momento incluye además, no solo los nombres de Ernesto y de su hermano, sino también una fotografía en blanco y negro de la familia Semán, "la única imagen existente de nuestra familia en pleno. La foto que había sobrevivido a todo, incluidos nosotros mismos. En el reverso, escrito en letra cursiva y firme y apurada, con una lapicera negra, podía leerse: 'Elías Semán, Susana Bodner, y sus hijos Pablo y Ernesto. Villa General San Martín, Rosario, octubre de 1969"' (183).

Rubén y su hermano, Agustín, encuentran la fotografía en una caja que su madre les dejó como legado para que abrieran después de su muerte. En clara desobediencia al deseo materno los hermanos deciden revisar el contenido de esa carta mientras Rosa duerme. Junto a la fotografía encuentran además un manojo de dólares, una carta de su abuelo, y Chinastro, el juguete que Luis le había traído a Rubén de China y que da nombre a la novela ("Soy un bravo piloto de la Nueva China" es la inscripción en Mandarín que tiene el avioncito en miniatura). En la caja también hay una larga carta que Luis escribió a Rosa en 1961, muy similar a las cartas testimonio y testamento que muchos militantes les dejaron a sus familias para explicar las razones que los llevaron a abrazar la lucha armada.

A contramano de lo que podría suponerse, no obstante, ni la introducción de los nombres reales de la familia del autor, ni esta fotografía, ni la carta (que bien podría ser la reproducción de una carta "real") son la constatación del carácter autobiográfico de la historia. Por un lado, el informante de Capitán declara que "Elías Semán y Susana Bodner" son nombres de guerra, es decir, nombres de fantasía, sin correspondencia en el registro jurídico de las personas. En la historia, esos nombres no tienen así un referente en el mundo empírico sino que cumplen la función de ocultar y proteger los verdaderos nombres, es decir los nombres reales, de los militantes Luis Abdela y Rosa, dentro de la lógica del universo narrativo-ficcional de la historia.

Por otro lado, la fotografía, como la carta, no produciría para Semán un "efecto real" sino más bien un "efecto (auto)ficcional": "esa parte real hacía mucho más fuerte la ficcionalización de todo el resto" (Friera, 2011). Pero además, si bien las fotos son, para muchos hijos de desaparecidos, el contacto más directo con el pasado (recordemos sino la imagen barthesiana (1993) de la foto como cordón umbilical entre el pasado representado y el presente en que se la mira), las fotos son, en rigor, aproximaciones y mediaciones.

Incluso el mismo Barthes, en su autobiografía (una autoficción que se publica en 1975, dos años antes de que Serge Doubrovsky publicara Fils, donde acuña el término "autoficción"), reconoce el carácter ficcional de las fotografías familiares. Roland Barthes por Roland Barthes, tal es el nombre del libro, empieza con un epígrafe que advierte: "Todo lo que está escrito aquí debe ser considerado como si hubiera sido dicho por un 
personaje en una novela" (1977: 3). Luego Barthes refuerza esta idea al titular un retrato fotográfico familiar similar al de Semán, "Novela familiar". Este título parecería, a su vez, dar crédito a las declaraciones del autor de Un bravo piloto... sobre las familias: "Las familias son narraciones de una serie de historias en las que lo que más importa son las ficciones que mantienen a la familia unida, traumática o felizmente, que lo que efectivamente pasó" (Friera, 2011).

Es decir, que tanto para Semán como para Barthes, incluso las familias "reales" están atravesadas por ficciones. $\mathrm{O}$ mejor, no hay familia sin ficciones pues estas se construyen con historias, con palabras, del mismo modo que las fotografías no dejan constancia de familias ya constituidas sino que, como sugiere Mary Bouquet (2000), fundan visualmente el parentesco.

Además de dar cuenta del lugar de la ficción en la fundación de la institución familiar, la autoficción o autofabulación del yo le permite a Semán contar parte de su historia -traumática, dolorosa- desde un lugar distinto a la posición a veces incómoda de la víctima. En su lugar la novela le permite hablar del pasado y legitimar su palabra no tanto (o no solo) en su condición de afectado directo del terrorismo de Estado, sino de joven escritor y storyteller, no tanto como "cuerpo sufriente" sino como "cuerpo creador", para decirlo con Alain Badiou.

De allí que Soy un bravo... establezca implícitos diálogos con la literatura de reconocidos escritores argentinos -en particular con la de sus "padrinos literarios": Sylvia Molloy y Ricardo Piglia- que posicionan la novela no al lado de la literatura testimonial sobre el terrorismo de Estado, sino dentro de una tradición (¿iuna familia?) literaria de ficciones que ya ha establecido determinadas operaciones discursivas, pero también elecciones políticas, para narrar el período dictatorial.

Por un lado, Soy un bravo piloto de la nueva China tiene varios puntos en común con Desarticulaciones (2011), una suerte de poemario en prosa, diario o cuaderno de bitácora publicado el mismo año que la novela de Semán, en el que Molloy combina ficción y testimonio para relatar el deterioro de M.L., una amiga y ex pareja de la autora que sufre de Alzheimer. Además del carácter autoficcional de la narración, ambas historias tratan sobre la recuperación de una memoria bajo amenaza de desaparecer.

Desarticulaciones está, en efecto, escrita a contrarreloj, con la esperanza de que la escritura se convierta en un reservorio para la memoria de M.L., que se extingue progresivamente con el correr del tiempo: "Tengo que escribir estos textos mientras ella esté viva, mientras no haya muerte o clausura, para tratar de entender ese estar/no estar de una persona que se desarticula ante mis ojos" (9). De igual modo, en Soy un bravo..., la madre de Rubén tiene poco tiempo de vida. Sus relatos son así piezas fundamentales del rompecabezas del pasado para Rubén y su hermano, pues saben que con ella también morirá una parte del recuerdo de Luis y de los años anteriores a sus nacimientos. 
En este aspecto la novela de Semán se asemeja también a otros relatos de las generaciones de la postdictadura. Enfermedades que suponen la pérdida de la memoria o inminentes muertes de los sobrevivientes adultos de las dictaduras latinoamericanas habitan, en efecto, las páginas de muchos de sus historias. En otra autoficción, Bosque quemado, de Roberto Brodsky, por ejemplo, el hijo de un cardiólogo exiliado judío de la dictadura chilena acompaña a su padre en el retorno a la tierra natal, mientras que una enfermedad amenaza con dejarlo desmemoriado. Así lo explica el médico que lo diagnostica: "Es un bosque quemado (...) Imaginen que su cerebro fue víctima de un incendio que arrasó con sus recuerdos, referencias, memoria, todo. El único consuelo que puedo dar es que él no lo sabe" (2008: 124). Otro ejemplo es el documental chileno Reinalda del Carmen, mi mamá y yo (2007), donde la directora, Lorena Giachino Torrens, se propone estimular los recuerdos de su madre (quien sufre periódicas crisis que conllevan pérdida de memoria) en la reconstrucción de la historia de Reinalda del Carmen, una amiga de la madre de Giachino Torrens desaparecida durante la dictadura.

En todos estos casos son las nuevas generaciones las que toman la posta de los recuerdos de los sobrevivientes adultos para asegurar su transmisión en forma de memoria cultural. Pero esta tarea no es fácil. Molloy sintetiza de este modo el problema mayúsculo que supone contar los recuerdos de otro para quienes no vivieron los hechos, o los vivieron de muy pequeños: “CCómo dice yo el que no recuerda, cuál es el lugar de enunciación cuando se ha destejido la memoria?" (19). La autoficción se presenta entonces como una posible respuesta a ese interrogante: "No quedan testigos de una parte de mi vida, la que su memoria se ha llevado consigo -leemos en Desarticulaciones-. Esa pérdida que podría angustiarme curiosamente me libera: no hay nadie que me corrija si me decido a inventar" (23).

Una de las características más atractivas de la autoficción para narrar el pasado doloroso es así su capacidad de liberar a los sujetos de todo tipo de condicionamientos y juicios de valor, pues nadie puede juzgar como verdadero o falso un recuerdo que se presenta desde el vamos como invención. Se trata, en definitiva, de una suerte de antídoto contra aquellos que todavía hoy discuten quién tiene derecho a tomar la palabra sobre el pasado, y con qué estrategias narrativas o géneros discursivos debería contarse el trauma de la desaparición.

En Soy un bravo piloto de la nueva China la propiedad del recuerdo y de quien es dueño de la verdad sobre el pasado es un tema central de la trama. Hay una escena en particular que se refiere explícitamente a esta cuestión. Rubén está en La Isla viendo una escena de su infancia en una computadora. Cuando termina la escena desenchufa el USB donde se almacenan esos recuerdos y sale a pasear. Entonces se le aparece Rudolf y le exige que le devuelva el dispositivo: "La escena me la quedo yo. Del pasado, los trajes y las tragedias" (76). "Pero las hice yo", le contesta Rubén. "No se nota", responde Rudolf, y agrega: " ¿vos sabés si existe un copyright de lo que uno recuerda? Pero no de los 
contenidos, sino de su sentido, del mundo enero que incluye ese recuerdo. ${ }_{\mathrm{C}} \mathrm{O}$ lo puede usar cualquiera?" (76).

Desde ${ }_{i}$ Sueñan los androides con ovejas eléctricas. (Dick, 1968) en adelante, la ciencia ficción ofreció los mejores ejemplos del género ensayando respuestas a la pregunta por la propiedad de los recuerdos. El campo de los estudios sobre memoria cultural, a su vez, se ha alimentado del imaginario de estas ficciones futuristas y distópicas para acuñar términos como "memoria prostética" (Landsberg, 2004) que intentan dar respuestas a la cuestión de la transmisión generacional cuando no haya más sobrevivientes de los eventos en cuestión. En Desarticulaciones ML no recuerda nada de lo que le dice y entonces la narradora piensa que tal vez sería mejor contarle el recuerdo como si fuera un relato nuevo, de otro, "que no pide identificación ni reconocimiento" (32).

También en este sentido, Soy un bravo piloto de la nueva China ficcionaliza no solo los recuerdos del autor sino que imagina además dos experiencias/memorias difíciles de imaginar: la del perpetrador (Capitán) y la del desaparecido (Luis). Al respecto, Semán explica en una entrevista que "una cosa que me interpelaba es (la idea de que) la historia es la suma de todas esas memorias", las de las víctimas pero también las de sus verdugos. Y agrega que uno de los desafíos más difíciles para él fue "desarrollar una empatía por ese otro que te parece incomprensible, pero ante quien necesitás saber por qué hizo lo que hizo, y sólo en ese contexto podía imaginar el dolor del torturador. Sin establecer ningún tipo de equivalencia moral sobre los lugares de cada uno, pero sí buscando respuestas que fueran más allá del lugar del hijo" (Friera, 2011).

Es esta forma de entender las relaciones entre memoria, historia y ficción la que permite establecer un diálogo entre la novela de Semán y la literatura de Ricardo Piglia. Por un lado, la concepción de la historia como un entramado de voces, ficciones y memorias recuerda a la maquina-mujer hacedora de relatos de la Ciudad ausente (1992) y a la idea de que "la realidad está tejida de ficciones" (Piglia, 1993: 17). Asimismo, en la reconocida novela de Piglia también hay una Isla (en las afueras de la ciudad), que es un sitio imaginario y utópico, destino en este caso de exiliados políticos. Pero además en la construcción del personaje de Capitán, Semán parece hacerse eco de la conocida afirmación de Piglia sobre autobiografía y ficción, según la cual la primera nace, en la Argentina, para narrar la civilización y la propia clase (el Facundo de Sarmiento), mientras que la segunda ("El matadero"), nace "en el intento de representar el mundo del enemigo, del distinto, del otro (...) esta representación supone y exige la ficción” (1993: 9) ${ }^{1}$.

\footnotetext{
${ }^{1}$ En rigor Soy un nuevo piloto de la nueva China no adapta simplemente la fórmula de Piglia sino que la reescribe en clave autoficcional, según la cual la ficción no es opuesta sino articulada con la autobiografía. En este sentido la novela de Semán también hace guiños a la autobiografía argentina per excellence, el Facundo de Sarmiento, no solo en la división campo-ciudad de los capítulos. Además, hacia el final de la historia, Rubén compara a su padre con el autor de Facundo, y el momento culminante en la vida de ambos donde citan mal: Sarmiento a Voltaire, Luis Abdela a
} 
¿Cómo imagina, entonces, Semán a este "otro"? Capitán tiene una moral monstruosa y la arrogancia de quien se cree dueño de la verdad. "La verdad soy yo" (120), dice en un momento sin medias tintas. En abierta provocación a concepciones de la tortura como las que ofrece Pilar Calveiro, para quien la tortura no solo deshumaniza al torturado sino también al torturador, ${ }^{2}$ Capitán no titubea en afirmar que "torturar es lo que nos hace más humanos" (230). Y es precisamente un torturador "humano", no un monstruo sino un hombre banal, el que quiere ofrecer Semán, en la línea del Villa de Luis Gusmán o del Mosca de Martín Kohan.

Pero a diferencia de estos personajes y también de Vieira, un soldado de bajo rango en Soy un bravo piloto... que superado un rapto de consciencia pide acompañar a los detenidos en los "vuelos de la muerte", Capitán no es un perejil, un burócrata o un simple engranaje de la máquina desaparecedora, sino un hombre de convicción en lo que hace. No obstante, la novela sugiere (casi como una expresión de deseo) que incluso alguien como Capitán no puede escapar a las consecuencias de sus actos. Es que resulta imposible no leer la sordera de origen desconocido que le ataca durante tres años como una suerte de manifestación involuntaria y sintomática de la culpa. Y cuando finalmente se recupera, en un claro acto de justicia poética, Capitán es asesinado por su hijo, Fausto. La novela no lo dice pero sí lo sugiere una nota en el diario reproducida en el epílogo, que la decisión de Fausto habría estado motivada por la responsabilidad del padre en los crímenes de la dictadura.

Así, el peor destino para un hombre, parece entonces insinuar Soy un bravo piloto de la nueva China, no es la muerte, ni siquiera la desaparición, sino el desprecio de los propios hijos. De este modo lo entiende también Luis, quien en conversación con Rudolf le dice que "lo que persigue a Capitán no es mi condena, es la de él mismo, saber cómo lo vemos todos. O preguntále cómo llegó acá, el gran tema del que no hemos hablado" (270). Luis se refiere, claro, a cómo llegó Capitán a La Isla, ese infierno de reunión entre vivos y muertos, al que el torturador arriba presuntamente después de haber sido asesinado por Fausto.

Distinto es el caso de Luis, para quien La Isla no es tanto un infierno como un lugar de reconciliación con su pasado, y en especial con Rubén. Toda la novela está atravesada por las tensiones entre militancia y vida familiar que definieron esa relación incluso antes del nacimiento de Rubén. En un momento, por ejemplo, Luis Abdela discute el embarazo de Rosa con el partido y le pide que no lo tenga porque "acceder a tener un hijo (léase yo), era un privilegio burgués inapropiado para quienes luchaban, precisamente contra los

Sartre. En todo caso sí es cierto que para Semán tanto como para Piglia, la ficción permiten imaginar la experiencia del otro, del perpetrador, en modos que al testimonio o la biografía le están vedados. 2 "Hay algo que se agita internamente en un hombre que destroza a otro. Hay algo que reclama la afirmación de su propia humanidad, porque en el intento de despersonalización de las víctimas él mismo se despersonaliza, se deshumaniza" (Calveiro, 2004: 72). 
privilegios burgueses" (105). Cuando Rosa decide tener a Rubén de todos modos, Luis no cambia su posición. En un determinado momento Rubén se enferma de bebé y Luis se niega a llevarlo al doctor después de decretar que "mi hijo se cure como un hijo de la villa". "Los hijos de la villa no se curan, pelotudo - le reprocha mentalmente Rubén - Se mueren, la putísimas madre que te parió (...) le dije desde mi cuerpo enfermizo, pálido, articulando un lenguaje por venir" (105). Como estas escenas dejan en evidencia, la autoficción le permite a Semán discutir con los muertos. Y es que "discutir con los muertos siempre es reconfortante" (76), aunque sepa que "el diálogo es siempre un malentendido" (247). Se trata, en definitiva, de ajustar cuentas pendientes con el pasado ${ }^{3}$.

Aunque nunca se produce un encuentro frente a frente entre padre e hijo (Rubén es espectador de las escenas donde aparece Luis, nunca participante), toda la novela podría entenderse como ese diálogo imposible entre generaciones, tal como lo adelantamos en las primeras líneas. Incluso hay, hacia el final del relato, un largo soliloquio de Luis o "Abdela el Cristiano", como lo llama Capitán, que está indirectamente dedicado a sus hijos y que bien podría leerse como respuesta a esa Carta al Padre que, según Piglia, es Soy un bravo piloto de la nueva China.

En ese soliloquio Capitán perdona a su torturador y pide perdón "a los que defraudé y a mí mismo, a todo lo que no alcancé" (269). Es ese pedido de perdón imaginario el que permite leer la novela como una "historia de amor" (Gaguine, 2011) y de construcción de futuro ("Mi perdón es el futuro", dice Luis en un momento). Pocas páginas atrás, Rubén había dejado de ver a su padre como un "psicópata" (194), para reconocerle a su hermano que "el viejo no era un santo pero comparado con el mundo que lo rodeaba era un gran ser humano" (196). Más tarde incluso confiesa que "hasta ahora no había pensado en el dolor de mi padre, así de simple. En lo terrible que tiene que haber sido para él" (272). Soy un bravo piloto de la nueva China es también, de algún modo, ese intento por ponerse en el lugar del padre.

Pero ni la lectura de la novela como una "historia de amor", ni esta idea de "reconciliación" suponen una clausura sentimentalista de la trama o una invitación al lector a identificarse con el dolor de las víctimas del terror estatal. En las últimas páginas Semán pone a trabajar todo su ingenio, imaginación y humor negro en uno de los parlamentos más audaces y desopilantes de la novela para reafirmar el carácter literario de la historia y relativizar su estatuto testimonial.

Rudolf, que se autodefine como un "entrepeneur" (270) antes que como un intelectual, le propone a Luis Abdela asociarse en un prolífico negocio del "mercado de la memoria". Se trata de un "Reconciliation Tour", una idea inspirada en los "dark tours" de Alemania que invitan a recorrer las oficinas de la Stasi y apreciar los archivos y autos

\footnotetext{
${ }^{3}$ La posibilidad que ofrece la autoficción de hablar con los muertos ya había sido utilizada unos años antes por Pablo Spinella (2009), también hijo de desaparecidos, en una novela algo más convencional que la de Semán.
} 
Trabant de los comunistas. En la versión local, el tour incluiría el reacondicionamiento de unos diez Falcon verde con el sponsorship de la marca ("todo industria nacional, na-cional, obvio" (264)), la participación de desaparecidos y una decena de represores ("lo importante es que sean tipos que hayan participado de verdad en la represión. Y por supuesto que hayan sido absueltos por la justicia, ¿no? No queremos ningún incidente judicial" (264)). El tour empezaría en Plaza de Mayo, con la ronda y una o dos Madres contando su historia, luego los turistas serían trasladados a los campos de concentración en los Falcon verde y acompañados por represores y desaparecidos que contarían la historia de una víctima "tipo". Al final del recorrido los turistas tienen la posibilidad de visitar el negocio y comprar el merchandising del trauma, un poco "como en los museos de Estados Unidos" (265). Basta recordar los camiones de bomberos de juguetes que venden hoy en la tienda de Ground Zero para advertir que la idea ni es tan descabellada ni tan alejada de la realidad.

Este episodio lleva la ficcionalización de la propia experiencia hasta las últimas consecuencias, siguiendo el camino ya trazado por las autoficciones de Félix Bruzzone y de Mariana Eva Perez, y constatando lo que Beatriz Sarlo (2008) dijo de Los topos, esto es que la literatura (a diferencia del testimonio o la autobiografía) puede hablar de cualquier cosa del modo que se le antoje.

Estas licencias de la autoficción no son, como acaso podría suponerse, meras provocaciones. El soliloquio de Luis o el "reconciliation tour" son, por el contrario, distintas formas del duelo. De allí que Semán haya dicho en una entrevista que la suya no es una "novela de los setenta", sino una del año dos mil, y también que escribe para darle sentido a lo que vivió. En este sentido es que además Soy un bravo piloto de la nueva China afirma, una y otra vez, que la historia y la herencia no son tanto el pasado como lo que uno haga con él en el presente. 


\section{Bibliografía citada:}

Barthes, Roland (1977). Roland Barthes by Roland Barthes. Londres: MacMillan.

Barthes, Roland (1993). Camera Lucida. Londres: Vintage.

Sarlo, Beatriz. "Sobre Los topos". Perfil (7/12/2008).

Bouquet, Mary. "The Family Photographic Condition". Visual Anthropology Review 16 (2000): 2-18. DOI: 10.1525/var.2000.16.1.2

Brodsky, Roberto (2008). Bosque quemado, Barcelona: Mondadori.

Calveiro, Pilar (2004). Poder y desaparición. Los campos de concentración en Argentina. Buenos Aires: Colihue.

Doubrovsky, Serge (1977). Fils. Paris: Gallimard.

Doubrovsky, Serge (2012). "Autobiografía / verdad /psicoanálisis". Ana Casas (eda.) La autoficción. Reflexiones teóricas. Madrid: Arco.

Freira, Silvina. "Quise hacer un collage de distintos recuerdos y memorias". Página 12 (7/3/2011).

Gaguine, Daniel. "Escribo para darle sentido a lo que viví". Noticias urbanas (13/3/2011).

Landsberg, Alison (2004). Prosthetic Memory: The Transformation of American Remembrance in the Age of Mass Culture. New York: Columbia University Press.

Molloy, Sylvia (2011). Desarticulaciones. Buenos Aires: Eterna cadencia.

Piglia, Ricardo (1993a). Crítica y ficción. Buenos Aires: Fausto.

Piglia, Ricardo (1993b) La Argentina en pedazos. Buenos Aires: Ediciones de la Urraca.

Ricardo, Piglia. "Una estrella roja volando sobre Argentina". Radar Libros. Página/12, $(20 / 3 / 2011)$.

Semán, Ernesto (1999). Educando a Fernando. Como se construyó De la Rua Presidente. Buenos Aires: Planeta.

Semán, Ernesto (2011). Soy un bravo piloto de la nueva China. Buenos Aires: Mondadori. Spinella, Pablo (2009) La imposibilidad del olvido. Buenos Aires: Nuestra América. 